\title{
Effects of characterised Pseudomonas aeruginosa exopolysaccharides on adherence to human tracheal cells
}

\author{
N. MARTY, C. PASQUIER, J.-L. DOURNES, K. CHEMIN*, F. CHAVAGNAT†, M. GUINAND $\dagger$, \\ G. CHABANON, B. PIPY $\ddagger$ and H. MONTROZIER
}

Laboratoire de Microbiologie and * Laboratoire de Biologie Cellulaire, Université Paul Sabatier, Toulouse, †Laboratoire de Biochimie Microbienne, Université Claude Bernard, Villeurbanne, †Institut National de la Santé et de la Recherche Médicale CJF 9107 and §Laboratoire de Pharmacologie et Toxicologie Fondamentales CNRS, Toulouse, France

\begin{abstract}
This study evaluated, in vitro, the role of different Pseudomonas aeruginosa exopolysaccharides (EPS) in mediating adherence to human respiratory epithelial cells. Two mucoid and non-mucoid isogenic pairs of $P$. aeruginosa strains isolated from patients with cystic fibrosis (CF) and bronchiectasis were used. Adherence was tested with human tracheal epithelial cell lines from $C F$ and normal fetuses. The CF cells bound significantly more bacteria than the normal cells. The strain from the bronchiectasis patient was significantly more adherent than that from the CF patient and this difference was consistently most marked with the non-mucoid variant and with normal epithelial cells. The differing behaviour of mucoid $C F$ and non-mucoid bronchiectasis strains reflected the chemical composition of their EPS: mainly alginate in the former and neutral polysaccharides in the latter. Additive inhibition experiments with chemically characterised EPS indicated that neutral polysaccharides associated with alginate may act as ligands for the adherence of $P$. aeruginosa to CF epithelial cells.
\end{abstract}

\section{Introduction}

Pseudomonas aeruginosa is a common human respiratory pathogen and is particularly important as a cause of chronic respiratory infections in cystic fibrosis $(\mathrm{CF})$ and bronchiectasis. Two mechanisms contribute to the complex pathogenesis of these respiratory infections. First, bacterial adhesion to the respiratory epithelial cells initiates infection [1]. Secondly, inhibition of phagocytosis by macrophages and polymorphonuclear leucocytes favours progression [2]. During both infections, the $P$. aeruginosa strains become mucoid by secreting an exopolysaccharide (EPS) containing alginate [3]. The molecular basis of this association is not known. $P$. aeruginosa EPS is a complex mucoid exopolysaccharide composed not only of alginate but also of other polysaccharides, and a knowledge of its chemical composition is essential to understanding its role in adherence. Several studies have shown that alginate is produced not only by mucoid $P$. aeruginosa but also, in smaller amounts, by non-mucoid isolates, including nonmucoid revertants of mucoid strains [4-6].

Received 4 Feb. 1997; revised version received 29 May 1997; accepted 11 June 1997.

Corresponding author: Dr N. Marty.
Alginate is among the numerous exoproducts and virulence factors produced by $P$. aeruginosa. It has been reported as playing a role in the adhesion of the bacterium to epithelial cell surfaces. In particular, it seems to be the adhesin for tracheal cells [7] and for tracheobronchial mucins [8]. However, some discrepancies are apparent: alginate purified from some $P$. aeruginosa strains binds to buccal and tracheal epithelial cells, whereas alginate from other strains does not do so, maybe reflecting structural diversity [9]. In a recent study, Ramphal et al. [10] showed several classes of adhesins on the surfaces of mucoid and nonmucoid $P$. aeruginosa, not only alginate and pilin, but also other adhesins requiring an alternative sigma factor. Other authors [11] have suggested the presence of such a 'dependent' adhesin in the adherence of $P$ aeruginosa cells to human lung pneumocytes. A recent review [12] emphasised that alginate does not represent a major ligand to the respiratory epithelium.

A previous study extracted and characterised different EPSs from mucoid and non-mucoid $P$. aeruginosa strains isolated from $\mathrm{CF}$ and bronchiectasis [5]. These differed in the alginate and neutral sugar content, and in the degree of $\mathrm{O}$-acetylation of the alginate. A recent study showed [13] that the alginate and neutral 
polysaccharides content of $P$. aeruginosa EPS may influence susceptibility to phagocytosis and to the macrophage oxidative burst. Less is known about the relationship between the chemical composition of the EPS and adherence. In view of the specific cellular receptors in $\mathrm{CF}$, the role of EPS may not be very significant. Nevertheless, the injured respiratory epithelium binds mucoid $P$. aeruginosa more readily than intact respiratory epithelium [14, 15] and Woods et al. [16] showed that buccal epithelial cells from CF patients bound greater numbers of $P$. aeruginosa cells than those from healthy individuals. Recently, Saiman [17] demonstrated a difference between the binding of $P$. aeruginosa to cell lines and primary polyp nasal cells from $\mathrm{CF}$ and non-CF origins.

This study determined the ability of two mucoid and non-mucoid isogenic pairs of $P$. aeruginosa strains to adhere in vitro to monolayers of human tracheal epithelial cells and compared their adherence to $\mathrm{CF}$ and normal cell lines. It also investigated the potential role of chemically different exopolysaccharides extracted from $P$. aeruginosa in mediating this adherence.

\section{Materials and methods}

\section{Bacteria}

Two mucoid $P$. aeruginosa strains isolated from sputa were used, one from a $\mathrm{CF}$ patient (M-CF) and one from a bronchiectasic patient (M-BR). The two corresponding isogenic non-mucoid derivaties (nM-CF and nMBR) were spontaneous variants and were used for comparison. All these organisms were non-piliate, and have been studied previously [5]. O-Serotyping by the International Antigenic Typing System showed similar results within both pairs: the $C F$ pair were of serotype 10 and the pair from the bronchiectasis patient were polyagglutinating.

Bacteria labelled with $\left[{ }^{3} \mathrm{H}\right]$ uracil were obtained by inoculating one colony from an overnight $37^{\circ} \mathrm{C}$ culture on Pseudomonas Isolation Agar (PIA; Difco, France) into $5 \mathrm{ml}$ of Bacto Nutrient Broth (NBY; Difco) containing labelled uracil (Amersham, France) $20 \mu \mathrm{Ci} / \mathrm{ml}$. This culture was incubated at $37^{\circ} \mathrm{C}$ for $18 \mathrm{~h}$ without agitation. The bacteria were then washed twice with phosphate-buffered saline (PBS; $140 \mathrm{mM} \mathrm{NaCl}, 10 \mathrm{mM}$ phosphate buffer, $\mathrm{pH}$ 7.4) containing unlabelled uracil $100 \mathrm{mg} / \mathrm{L}$, then resuspended in PBS $(5 \mathrm{ml})$. The viable count was adjusted to $10^{9} \mathrm{cfu} / \mathrm{ml}$ and the radioactivity associated with the cells was evaluated in a liquid scintillation counter (Pharmacia LKB1217 Rackbeta).

\section{Determination of chemical content of the EPS}

The chemical composition of the EPS from the four organisms was determined by gas-liquid chromatography and ${ }^{1} \mathrm{H}-\mathrm{NMR}$ spectroscopy, as described previously [5]. In addition, EPS from Laminaria hyperborea, a brown seaweed, was used; this was kindly provided by Sobalg SA, Landerneau, France. In some experiments, the neutral and acidic fractions obtained after chromatography of the EPS on DEAE-Trisacryl were tested, after elution with $0.1 \mathrm{M}$ and $0.8 \mathrm{M} \mathrm{NaCl}$, respectively.

\section{Preparation of cell monolayers}

Two human tracheal epithelial cell lines transfected with SV40 virus were used. Both were from fetuses, one normal (NT cells) and the other with CF. The CF cells were homozygous for the most common deletion, $\triangle$ F508 and were kindly provided by J. Picard, Unité 181, Institut National de la Santé et de la Recherche Médicale, Paris. In adherence assays, the cells were used after nine to 15 passages. Under these conditions, they retained typical epithelial morphology, and the CF cells exhibited the abnormal regulation of chloride conductance characteristic of the disease [18]. Plastic microtitration plates (Costar, France) containing sterile glass coverslips to prevent adherence of $P$. aeruginosa cells to the plastic were used to prepare the cell monolayers: $400 \mu \mathrm{l}$ of the epithelial cell suspension were layered on to the $10-\mathrm{mm}$ diameter glass coverslips in 48 -well plates and incubated for 5 days in a $\mathrm{CO}_{2}$ incubator. The morphology, confluence and condition of the monolayers were studied by light microscopy after MayGrünwald and Giemsa staining. The cells were washed twice with DMEM (Gibco, France) (44 mM $\mathrm{NaHCO}_{3}$ buffer, $\mathrm{pH}$ 7.2) immediately before use.

\section{Adherence assays}

Radiolabelled bacterial suspensions $(50 \mu 1)$ were applied to the cell layers and incubated for $60 \mathrm{~min}$ at $37^{\circ} \mathrm{C}$ in a atmosphere of air $95 \%, \mathrm{CO}_{2} 5 \%$. The cell monolayers on the coverslips were then washed three times with warm $\left(37^{\circ} \mathrm{C}\right) \mathrm{PBS}$ to remove non-adherent bacteria. The coverslips were removed and placed in individual vials, where cell-associated radioactivity was released by adding $150 \mu \mathrm{l}$ of $1 \mathrm{~N} \mathrm{NaOH}$, followed by neutralisation with $150 \mu \mathrm{l}$ of $1 \mathrm{~N} \mathrm{HCl}$. The radioactivity in 5-ml amounts of scintillation liquid (Amersham) was then counted in a liquid scintillation counter as previously described [19]. After each test of adherence, the coverslips were air-dried and examined by light microscopy with May-Grünwald and Giemsa staining. Bacterial counts were expressed as adherent bacterial $\mathrm{cfu} /$ well based on the means and SD of four separate experiments, each performed in quadruplicate.

\section{Inhibition experiments}

Studies on the inhibition of adherence by EPS and its fractions were performed with the nM-BR $P$. aeruginosa strain, which was the most adherent of the four organisms. Cell monolayers were preincubated for $30 \mathrm{~min}$ at $37^{\circ} \mathrm{C}$, in $\mathrm{CO}_{2} 5 \%$ with $250 \mu \mathrm{l}$ EPS or EPS fraction $(1 \mathrm{mg} / \mathrm{ml})$ instead of the $250 \mu \mathrm{l}$ of DMEM medium, then the radiolabelled bacteria were added 
and the binding assay was continued in the usual way. Results were expressed as mean percentage inhibition of binding and $\mathrm{SD}$, based on four separate experiments, each performed in quadruplicate.

To assess the role of alginate, mixed (i.e., alginatecontaining) EPS was treated with an alginase obtained from the marine bacterium ATCC 433367, which is able to hydrolyse $P$. aeruginosa alginate isolated from $\mathrm{CF}$ patients [20]. The EPS was incubated for $18 \mathrm{~h}$ at $37^{\circ} \mathrm{C}$ with the alginase $(0.13 \mu \mathrm{g}$ of enzyme $/ \mathrm{mg}$ of EPS; specific activity, 80 units/mg of protein) before addition to cell monolayers. The enzyme activity was checked by measuring the increase of optical density at $235 \mathrm{~nm}$, which assesses formation of unsaturated uronic acids. One enzyme unit produced $1 \mu \mathrm{mol}$ or unsaturated termini per min, with 3-deoxy-D-mannooctulosonic acid (Sigma) as the standard. Results were compared with those observed with alginase the untreated EPS.

\section{Statistical analysis}

Data are expressed as means and SEM, and statistical significance was assessed with Student's $t$ test for unpaired observations.

\section{Results}

The surface characteristics of the $P$. aeruginosa cultures and the chemical composition of their EPS in the culture medium used are described in Table 1. Neither of the bronchiectasis organisms, but both CF organisms produced alginate. On the other hand, both the bronchiectasis organisms produced a neutral EPS composed of neutral sugars including rhamnose, mannose, glucose, galactose, $\mathrm{N}$-glucosamine and $\mathrm{N}$-galactosamine.

\section{Bacterial adherence to human tracheal epithelial cell monolayers}

As shown in Fig. 1, adherence was time-dependent, with the number of adherent bacteria increasing progressively during the first hour of contact, then reaching a maximum which thereafter remained constant. On this basis, an incubation period of $60 \mathrm{~min}$ was selected for further experiments. As shown in Table 2,

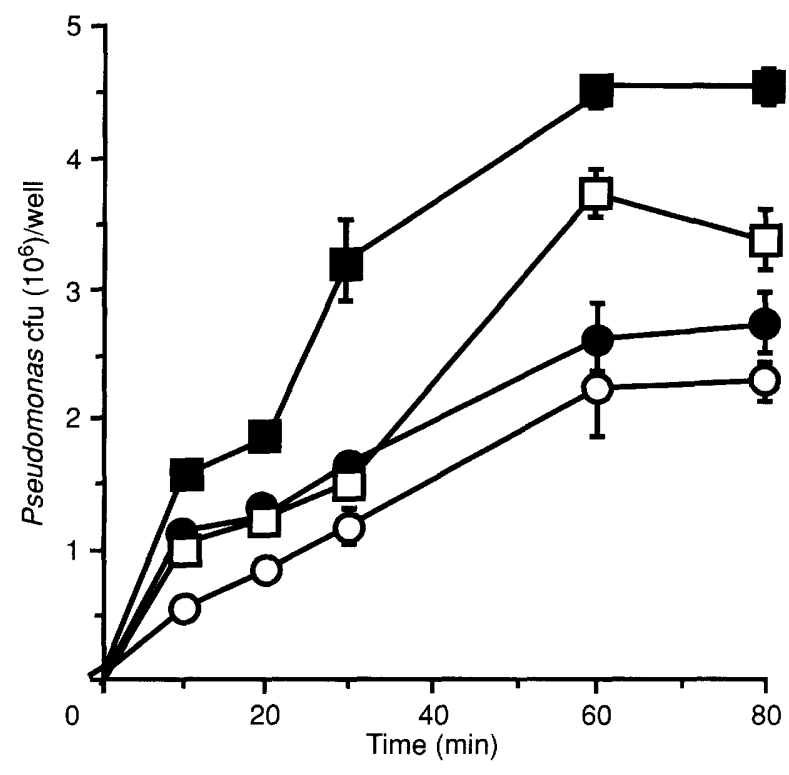

Fig. 1. Kinetics of adherence of $P$. aeruginosa to $\mathrm{CF}$ cells. Radiolabelled bacterial suspensions $(50 \mu \mathrm{l})$, adjusted to $10^{9} \mathrm{cfu} / \mathrm{ml}$, were incubated with tracheal epithelial cells for different periods. Results represent the means and SD of four experiments at each time interval. Results are for organisms as follows: $-\square-, n M-$ $\mathrm{BR} ;-\square-, \mathrm{M}-\mathrm{BR} ;--$, nM-CF; -O-, M-CF.

Table 2. Comparison of adherence of $P$. aeruginosa to $\mathrm{CF}$ and normal cell monolayers

\begin{tabular}{lccc}
\hline & \multicolumn{3}{c}{$\begin{array}{c}\text { Mean (SD) adherence to epithelial } \\
\text { monolayers* }\end{array}$} \\
\cline { 2 - 3 } $\begin{array}{l}\text { P. aeruginosa } \\
\text { strain }\end{array}$ & CF-cells & normal cells & p \\
\hline$n y y n$ & $46(2)$ & $12(2)$ & $<0.001$ \\
nM-BR & $38(1)$ & $7(1)$ & $<0.001$ \\
nM-BR & $25(1)$ & $2(0.1)$ & $<0.001$ \\
M-CF & $21(5)$ & $2(0.1)$ & $<0.001$ \\
\hline
\end{tabular}

${ }^{*}$ Adherence is expressed as the mean number (SD) of adherent bacteria $\left(\times 10^{5}\right) /$ well, as estimated from the radioactivity remaining on the cell monlayer after $60 \mathrm{~min}$ of contact, as indicated in Materials and methods.

the CF cells bound significantly more bacteria than did normal cells $(\mathrm{p}<0.001)$. The bronchiectasis organisms, especially nM-BR (Fig. 1), demonstrated greater rates of adherence to the $\mathrm{CF}$ epithelial cells than did the other cultures. The mucoid bronchiectasis strain was significantly less adherent than its non-mucoid revertant $(\mathrm{p}<0.01)$.

Table 1. Chemical composition of the EPS of the four mucoid and non-mucoid $P$. aeruginosa strains used in adherence assays

\begin{tabular}{|c|c|c|c|c|c|c|c|c|c|}
\hline \multirow[b]{2}{*}{ Strain } & \multicolumn{6}{|c|}{ Relative molar ratio of sugars composing the EPS* } & \multirow[b]{2}{*}{ Alginate $(\%)^{*}$} & \multicolumn{2}{|c|}{ Characteristics of the alginate } \\
\hline & Rha & Man & Gal & Glc & GalN & GlcN & & $\mathrm{M} / \mathrm{G}$ ratio $^{\dagger}$ & O-acetyl $(\%)^{\dagger}$ \\
\hline $\mathrm{M}-\mathrm{CF}$ & 1 & 0.3 & 1 & 1 & 1 & 0.1 & 70 & $89 / 11$ & 37 \\
\hline $\mathrm{nM}-\mathrm{CF}$ & 0.14 & 0.01 & 0.04 & 1 & 0.18 & 0.16 & 33 & $79 / 21$ & 46 \\
\hline M-BR & 1 & 0.2 & 0.03 & 1 & 0 & 0.1 & $<1$ & - & - \\
\hline nM-BR & 0.2 & 0.02 & 0.04 & 1 & 0.2 & 0.3 & $<1$ & - & - \\
\hline
\end{tabular}

*Estimated by GLC of the methylglycosides from the methanoloysis of EPS, as described previously [5]. Rha, rhamnose; Man, mannose; Gal, galactose; Glc, glucose; GalN, N-galactosamine; GlcN, N-glucosamine.

${ }^{\dagger}$ Ratio of D-mannuronic acid to L-guluronic acid and degree of acetylation, calculated from ${ }^{1} \mathrm{H}-\mathrm{NMR}$ spectra, as described previously [5]. 
There was a correlation between the predominance of neutral sugars in the EPS (Table 1) and the extent of bacterial adherence: non-mucoid $P$. aeruginosa adhered better than the mucoid strains.

\section{Influence of EPS components on bacterial adherence to human tracheal epithelial cells}

Each of five EPS preparations tested decreased the adherence of $P$. aeruginosa nM-BR strain to human tracheal cells compared with control cultures (Table 3 ). EPS from organisms M-BR-1 and M-BR-2 contained more neutral sugars than alginate and were the strongest inhibitors of adherence, causing a significant reduction in bacterial binding $(\mathrm{p}<0.001)$. Less pronounced inhibition of adherence was also seen with the EPS preparations from organisms M-CF and MBR-3, which predominantly contained alginate. The Laminaria EPS, which had a non-aceylated alginate with a high ratio of guluronic acid, did not influence adherence significantly.

The inhibition of the adherence by EPS was doserelated and only the preparations from organisms $M$ BR-1 and M-BR-2 remained inhibitory when diluted to $100 \mathrm{mg} / \mathrm{L}$, whereas the other EPS preparations ceased to inhibit adherence at concentrations below $500 \mathrm{mg} / \mathrm{L}$.

To investigate further the role of the various EPS components (alginate and neutral sugars) in affecting the adherence of $P$. aeruginosa, two control procedures were performed. First, the effect of treating the EPS with alginase was examined (Fig. 2). Alginase treatment reduced the inhibition of pseudomonal binding for each of the EPS preparations except that from organism M-BR-1, which was devoid of alginate. Nevertheless, EPS from organism M-BR-1, as well as that from M-BR-2 retained a significant ability to inhibit adherence of $P$. aeruginosa, even after the alginase treatment. For the other EPS preparations, the alginase caused loss of any significant ability to inhibit adhesion of $P$. aeruginosa. Secondly competition experiments tested the ability of neutral and acid

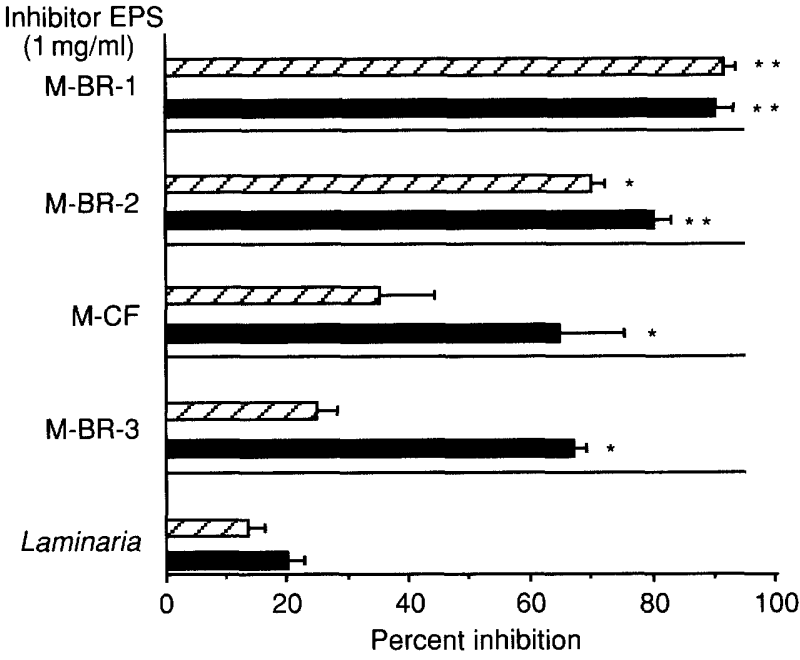

Fig. 2. Inhibition of the adherence to human tracheal epithelial cells of $P$. aeruginosa nM-BR by different EPS preparations and and reversal of this inhibition by alginase, 6 . The five EPS preparations were chosen as having different chemical compositions (see Table 3). Each bar represents the mean of quadruplicate experiments, and the error bar indicates the SD. ${ }^{* *} \mathrm{p}<0.001$ and ${ }^{*} \mathrm{p}<0.05$, by $t$ test, as compared to the control without EPS.

fractions of the EPS to inhibit adhesion of $P$. aeruginosa (Table 4). The neutral fractions significantly inhibited adherence whereas the acidic fractions did not do so.

\section{Discussion}

Adherence of bacteria isolated from $\mathrm{CF}$ bronchial secretions logically should be studied with cells in a state that most closely imitates the natural biology of the disease. In most studies, however, the adhesion support is an inert material such as dacron fibres [21] or normal respiratory cells from different animal species [22], or cells injured by acids [7]. Adherence to respiratory cells from CF patients has been littleinvestigated and, even then, often only with laboratory strains of $P$. aeruginosa. This study used $P$. aeruginosa

Table 3. Inhibition by five different EPS preparations of the adherence of the P. aeruginosa strain nM-BR to human tracheal epithelial cells

\begin{tabular}{|c|c|c|c|c|c|c|c|c|c|c|}
\hline \multirow[b]{2}{*}{ EPS tested* } & \multicolumn{6}{|c|}{ Relative molar ratio of sugars composing the EPS ${ }^{\dagger}$} & \multirow[b]{2}{*}{ Alginate $(\%)^{\dagger}$} & \multicolumn{2}{|c|}{ Characteristics of the alginate ${ }^{\dagger}$} & \multirow{2}{*}{$\begin{array}{l}\text { Inhibition of } \\
\text { adherence }^{\ddagger} \\
\% \text { (SD) }\end{array}$} \\
\hline & Rha & Man & Gal & Glc & GalN & GlcN & & $\mathrm{M} / \mathrm{G}$ ratio & O-acetyl (\%) & \\
\hline M-BR-1 & 0.17 & 0.2 & 0.03 & 1 & 0.02 & 0.01 & ND & - & - & $90(3)^{\S}$ \\
\hline M-BR-2 & 0.4 & 0.2 & 0.04 & 1 & 0.2 & 0.1 & 33 & $79 / 21$ & 46 & $80(3)^{\S}$ \\
\hline M-BR-3 & 1 & 0.2 & 0.03 & 1 & 0 & 0.1 & 83 & $97 / 3$ & 2 & $67 \quad(2)^{8}$ \\
\hline $\mathrm{M}-\mathrm{CF}$ & 1 & 0.3 & 1 & 1 & 1 & 0.1 & 70 & $89 / 11$ & 37 & $65(10)^{\|}$ \\
\hline Laminaria & ND & ND & ND & ND & ND & ND & 99 & $45 / 55$ & 0 & $20 \quad(5)$ \\
\hline
\end{tabular}

ND, not detected.

${ }^{*}$ Origin of the five EPS tested: the numbers correspond to different EPS types produced by the same $P$. aeruginosa strain on various culture media: Laminaria is the EPS produced by Laminaria hyperborea. These EPS preparations were chosen as having differences in chemical composition.

${ }^{\dagger}$ The chemical characteristics were determined by GLC and RMN spectroscopy, see Table 1.

${ }^{\ddagger}$ Data are means and SD based on four separate experiments performed in quadruplicate. Inhibitors were used at $1 \mathrm{mg} / \mathrm{ml}$. ${ }^{\S} \mathrm{p}<0.001$ and $\|_{p}<0.05$ compared with a control without EPS. 
Table 4. Inhibition of the adherence of the nM-BR $P$. aeruginosa strain to human tracheal epithelial cells by purified fractions of EPS

\begin{tabular}{llc}
\hline EPS & Purified fraction* & $\begin{array}{c}\text { Percentage (SD) inhibition } \\
\text { of adherence }\end{array}$ \\
\hline M-CF & Neutral & $61(4)^{\ddagger}$ \\
M-BR-3 & Acidic & $30(3)$ \\
& Neutral & $59(4)^{\ddagger}$ \\
& Acidic & $20(1)$ \\
\hline
\end{tabular}

${ }^{*}$ The neutral fraction (neutral sugars) and acidic fraction (alginate) were obtained by chromatography on DEAE-Trisacry with elution by $0.1 \mathrm{M}$ and $0.8 \mathrm{M} \mathrm{NaCl}$, respectively.

${ }^{\dagger}$ Data are means and SD based on at least four separate experiments performed in quadruplicate. All inhibitors were used at $1 \mathrm{mg} / \mathrm{ml}$. ${ }_{\mathrm{f}} \mathrm{p}<0.05$ compared with a control without EPS.

isolates from patients and monolayers of human cells and found a significant difference between their adherence to epithelial cells from $\mathrm{CF}$ and non-CF sources. The CF tracheal cells bound more bacteria than did the normal cells. Three previous studies have also found greater pseudomonal adherence to CF cells than to normal cells $[17,23,24]$, whereas one group [25] found no significant difference in vitro, but speculated that in vivo increased mucin secretion by cells from $\mathrm{CF}$ patients might favour binding of $P$. aeruginosa. Epithelial cells from $\mathrm{CF}$ patients differ from those of non-CF patients in permeability to chloride ions, in releasing more highly sulphated glycoconjugates, and in harbouring lower amounts of glycosylated glycoconjugates on the cell surface.

Several previous studies found that mucoid $P$. aeruginosa strains adhered better than non-mucoid variants to all cells $[21,22,26]$, but others found no difference $[1,27,28]$ or that mucoid forms bound less strongly $[10,16]$. These differences could be due to differences in the bacteria and cells used. With human isolates and human respiratory cell monolayers, this study found the non-mucoid variants significantly more adhesive.

Previous investigators have suggested that alginate mediates adherence of $P$. aeruginosa to various cells [7, 26, 29] but this has not been confirmed by showing that adherence could be inhibited by addition of free alginate. Moreover, some studies found that some alginates did not bind to buccal epithelial cells, probably reflecting structural diversity [9]. Moreover, to our knowledge, no previous group has really studied the relationship between the clinical composition of $P$. aeruginosa EPS and its role in adherence. The production of alginate, which is only one component of EPS, is highly regulated and is influenced by environmental and nutritional factors [30]. When the carbon source is changed, the yield of alginate may be altered dramatically [5]. Variability among $P$. aeruginosa alginates in terms of amount, chemical composition and idiotypic response had been underlined by Irvin et al. [31] and by Pedersen et al. [32]. The two types of EPS found in the present study
- alginate-containing and non-alginate containing are consistent with the study by McArthur et al. [33] who showed heterogeneity of EPS based on the presence or absence of neutral and amino-sugars (hexosamines) in addition to mannuronic and guluronic acids. These authors noted the presence of the same sugars as the present study found in the EPS with the greatest inhibitory effect, but did not demonstrate whether these components were substituents of the alginate or if there was more than one polymer present. The present results with the purified fractions indicate the presence of another of another polysaccharide, distinct from the alginate, and this is in agreement with another study [34]. We hypothesise that differences in alginate binding could be explained by the variable chemistry of this material. An alternative hypothesis, that binding was affected by lipopolysaccharides present as contaminants of the EPS, can be discarded, as the O-serotypes of the present strains were constant within the mucoid/nonmucoid pairs.

The predisposition of $\mathrm{CF}$ and bronchiectasis patients to respiratory infections with $P$. aeruginosa raises the possibility of specific interactions of the bacteria with the respiratory epithelium. Mucoid and non-mucoid variants have generally equal numbers of pili [35]. In the present study, all organisms were non-piliate (not shown). As for the role of mucoid EPS, alginate seemed to be an adhesin to injured mouse tracheal cells [7] and it was inferred that alginate functions as a bridge between the bacteria and the tracheal surface. These observations appear to be consistent with the results of the present study. Another study [36] on the tracheobronchial mucin receptor for $P$. aeruginosa underlined differences in the role of amino sugars, indicating that they influenced differences in binding between non-mucoid and mucoid strains, and among mucoid strains. Several other recent studies $[10,11$, 37] underline the possibility of pseudomonal adhesins other than pilin and alginate.

Alginase treatment decreased the ability of free EPS to inhibit the adherence of $P$. aeruginosa, but did not completely restore adherence, suggesting that alginate was one - but not the sole - EPS component involved in adhesion. Moreover, the neutral EPS fraction appeared to cause greater inhibition of pseudomonal binding than the acidic (alginate) fraction. Thus, the alginate may have only a marginal effect on the adherence of $P$. aeruginosa to respiratory epithelial cells and perhaps, rather, acts to form a matrix in which bacteria become embedded once adherence has taken place. This model has been proposed for the adherence of $P$. fluorescens to surfaces in freshwater [38], where a mucoid mutant also achieved lower levels of attachment than a nonmucoid wild type.

In conclusion, this study shows that the neutral 
polysaccharides, which together with alginate compose the $P$ a aruginosa EPS, are involved in adherence. The variability of adherence of mucoid $P$. aeruginosa may be explained in part by the presence, in variable quantities, of alginate and neutral polysaccharides. Further studies are required to assess the behaviour of these components: the alginate may act as a nonspecific bridge between cells and bacteria and the neutral polysaccharides could be specific adhesins in primary colonisation by non-mucoid $P$. aeruginosa in cystic fibrosis.

This work was supported by a grant from the Association Française de Lutte contre la Mucoviscidose. We thank also Pr E. Hollande for helpful advice. We are very grateful to Mary Fanning-Durrieu, Département de Langues Vivantes, who reviewed the English.

\section{References}

1. Boyd RL, Ramphal R, Rice R, Mangos JA. Chronic colonization of rat airways with Pseudomonas aeruginosa. Infect Immun 1983; 39: 1403-1410.

2. Speert DP, Loh BA, Cabral DA, Salit IE. Nonopsonic phagocytosis of nonmucoid Pseudomonas aeruginosa by human neutrophils and monocyte-derived macrophages is correlated with bacterial piliation and hydrophobicity. Infect Immun 1986; 53: 207-212.

3. Pedersen SS, Høiby N, Espersen F, Koch C. Role of alginate in infection with mucoid Pseudomonas aeruginosa in cystic fibrosis. Thorax 1992; 47: 6-13.

4. Anastassiou ED, Mintzas AC, Kounavis C, Dimitracopoulos G. Alginate production by clinical nonmucoid Pseudomonas aeruginosa strains. J Clin Microbiol 1987; 25: 656-659.

5. Marty N, Dournes J-L, Chabanon G, Montrozier H. Influence of nutrient media on the chemical composition of the exopolysaccharide from mucoid and non-mucoid Pseudomonas aeruginosa. FEMS Microbiol Lett 1992; 98: 35-44.

6. Pier GB, Desjardins D, Aguilar T, Barnard M, Speert DP. Polysaccharide surface antigens expressed by nonmucoid isolates of Pseudomonas aeruginosa from cystic fibrosis patients. J Clin Microbiol 1986; 24: 189-196.

7. Ramphal R, Pier GB. Role of Pseudomonas aeruginosa mucoid exopolysaccharide in adherence to tracheal cells. Infect Immun 1985; 47: 1-4.

8. Ramphal R, Guay C, Pier GB. Pseudomonas aeruginosa adhesins for tracheobronchial mucin. Infect Immun 1987; 55: 600-603.

9. Doig P, Smith NR, Todd T, Irvin RT. Characterization of the binding of Pseudomonas aeruginosa alginate to human epithelial cells. Infect Immun 1987; 55: 1517-1522.

10. Ramphal R, Koo L, Ishimoto KS, Totten PA, Lara JC, Lory S. Adhesion of Pseudomonas aeruginosa pilin-deficient mutants to mucin. Infect Immun 1991; 59: 1307-1311.

11. Chi E, Mehl T, Nunn D, Lory S. Interaction of Pseudomonas aeruginosa with A549 pneumocyte cells. Infect Immun 1991; 59: $822-828$.

12. Prince A. Adhesins and receptors of Pseudomonas aeruginosa associated with infection of the respiratory tract. Microb Pathog 1992; 13: 251-260.

13. Pasquier C, Marty N, Dournes J-L, Chabanon G, Pipy B. Implication of neutral polysaccharides associated to alginate in inhibition of murine macrophage response to Pseudomonas aeruginosa. FEMS Microbiol Lett 1997; 147: 195-202.

14. Plotkowski MC, Beck G, Tournier JM, Bernardo-Filho M, Marques EA, Puchelle E. Adherence of Pseudomonas aeruginosa to respiratory epithelium and the effect of leucocyte elastase. J Med Microbiol 1989; 30: 285-293.

15. Yamagushi $T$, Yamada $H$. Role of mechanical injury on airway surface in the pathogenesis of Pseudomonas aeruginosa. Am Rev Respir Dis 1991; 144: 1147-1152.

16. Woods DE, Bass JA, Johanson WG, Straus DC. Role of adherence in the pathogenesis of Pseudomonas aeruginosa lung infection in cystic fibrosis patients. Infect Immun 1980; 30: $694-699$.
17. Saiman L, Cacalano G, Gruenert D, Prince A. Comparison of adherence of Pseudomonas aeruginosa to respiratory epithelial cells from cystic fibrosis patients and healthy subjects. Infect Immun 1992; 60: 2808-2814.

18. Lemnaouar M, Chastre E, Paul A et al. Oncogene-mediated propagation of tracheal epithelial cells from two cystic fibrosis fetuses with different mutations. Characterization of CFT-1 and CFT-2 cells in culture. Eur J Clin Invest 1993; 23: 151-160.

19. Thardin JF, M'Rini C, Beraud M et al. Eicosanoid production by mouse peritoneal macrophages during Toxoplasma gondii penetration: role of parasite and host cell phospholipases. Infect Immun 1993; 61: 1432-1441.

20. Malissard M, Duez C, Guinand $M$ et al. Sequence of a gene encoding a (poly ManA) alginate lyase active on Pseudomonas aeruginosa alginate. FEMS Microbiol Lett 1993; 110: $101-106$.

21. Mai GT, McCormack JG, Seow WK, Pier GB, Jackson LA, Thong YH. Inhibition of adherence of mucoid Pseudomonas aeruginosa by alginase, specific monoclonal antibodies, and antibiotics. Infect Immun 1993; 61: 4338-4343.

22. Marcus H, Baker NR. Quantitation of adherence of mucoid and nonmucoid Pseudomonas aeruginosa to hamster tracheal epithelium. Infect Immun 1985; 47: 723-729.

23. Ferguson MI, Scott EM, Collier PS. Factors affecting quantitative assessment of Pseudomonas aeruginosa adherence to buccal epithelial cells. APMIS 1992; 100: 876-882.

24. Girod de Bentzmann S, Bajolet-Laudinat O, Dupuit F et al. Protection of human respiratory epithelium from Pseudomonas aeruginosa adherence by phosphatidylglycerol liposomes. Infect Immun 1994; 62: 704-708.

25. Plotkowski MC, Chevillard M, Pierrot D, Altemayer D, Puchelle E. Epithelial respiratory cells from cystic fibrosis patients do not possess specific Pseudomonas aeruginosaadhesive properties. J Med Microbiol 1992; 36: 104-111.

26. Marcus H, Austria A, Baker NR. Adherence of Pseudomonas aeruginosa to tracheal epithelium. Infect Immun 1989; 57: 1050-1053.

27. Baker N, Hansson GC, Leffier H, Riise G, Svanborg-Edén C Glycosphingolipid receptors for Pseudomonas aeruginosa. Infect Immun 1990; 58: 2361-2366.

28. Ramphal R, Pyle M. Adherence of mucoid and nonmucoid Pseudomonas aeruginosa to acid-injured tracheal epithelium. Infect Immun 1983; 41: 345-351.

29. Oliver AM, Weir DM. Inhibition of bacterial binding to mouse macrophages by Pseudomonas alginate. J Clin Lab Immunol 1983; 10: $221-224$.

30. May TB, Shinabarger D, Maharaj R et al. Alginate synthesis by Pseudomonas aeruginosa: a key pathogenic factor in chronic pulmonary infections of cystic fibrosis patients. Clin Microbiol Rev 1991; 4: 191--206.

31. Irvin RT, Ceri H. Immunochemical examination of the Pseudomonas aeruginosa glycocalyx: a monoclonal antibody which recognizes L-guluronic acid residues of alginic acid. Can J Microbiol 1985; 31: 268-275.

32. Pedersen SS, Espersen F, Høiby N, Shand GH. Purification, characterization, and immunological cross-reactivity of alginates produced by mucoid Pseudomonas aeruginosa from patients with cystic fibrosis. J Clin Microbiol 1989; 27: 691-699.

33. McArthrur HAI, Ceri H. Interaction of a rat lung lectin with the exopolysaccharides of Pseudomonas aeruginosa. Infect Immun 1983; 42: 574-578.

34. Ceri H, McArthur HAI, Whitfield C. Association of alginate from Pseudomonas aeruginosa with two forms of heparinbinding lectin isolated from rat lung. Infect Immun 1986; 51: $1-5$.

35. Cabral DA, Loh BA, Speert DP. Mucoid Pseudomonas aeruginosa resists nonopsonic phagocytosis by human neutrophils and macrophages. Pediatr Res 1987; 22: 429-431.

36. Vishwanath S, Ramphal R. Tracheobronchial mucin receptor for Pseudomonas aeruginosa: predominance of amino sugars in binding sites. Infect Immun 1985; 48: 331-335.

37. Saiman L, Ishimoto K, Lory S, Prince A. The effect of piliation and exoproduct expression on the adherence of Pseudomonas aeruginosa to respiratory epithelial monolayers. $J$ Infect Dis 1990; 161: 541-548.

38. Allison DG, Sutherland IW. The role of exopolysaccharides in adhesion of freshwater bacteria. $J$ Gen Microbiol 1987; 133: 1319-1327. 